\title{
Enhanced Controller Topology for Photovoltaic Sourced Grid Connected Inverters under Unbalanced Nonlinear Loading
}

\author{
P. Sivakumar ${ }^{*}$ and Meenakshi Sundaram Arutchelvi ${ }^{\dagger}$ \\ *Dept. of Electrical \& Electronic Engineering, J. J. College of Engineering and Technology, Tamil Nadu, India \\ ${ }^{\dagger}$ Dept. of Electrical \& Electronic Engineering, Saranathan College of Engineering, Tamil Nadu, India
}

\begin{abstract}
A growing dynamic electrical demand has created an increasing interest in utilizing nonconventional energy sources like Photovoltaic (PV), wind power, etc. In this context, this paper focuses on the design and development of a composite power controller (CPC) in the decoupled double synchronous reference frame (DDSRF) combining the advantages of direct power control (DPC) and voltage oriented control (VOC) for a PV sourced grid connected inverter. In addition, a controller with the inherent active filter configuration is tested with nonlinear and unbalanced loads at the point of common coupling in both grid connected and autonomous modes of operation. Furthermore, the loss and reactive power compensation due to a non-fundamental component is also incorporated in the design, and the developed DDSRF model subsequently allows independent active and reactive power control. The proposed developed model of the controller is also implemented using MATLAB-Simulink-ISE and a Xilinx system generator which evaluate both the simulated and experimental setups. The simulation and experimental results confirm the validity of the developed model. Further, simulation results for the DPC are also presented and compared with the proposed CPC to further bring out the salient features of the proposed work.
\end{abstract}

Key words: Composite power control Nonlinear unbalanced loading, Direct Power control, MATLAB-Simulink-ISE, PV array, Voltage oriented control

\section{NOMENCLATURE}

$C_{e f} \quad$ effective virtual capacitance

$i_{p v} \quad$ PV array current (A)

$i_{i p v} \quad$ current supplied from the PV source to the inverter (A)

$P_{i} \quad$ real power supplied from the PV sourced Inverter (W)

$Q_{i} \quad$ reactive power supplied from the PV sourced inverter (Var)

$P_{L} \quad$ real power absorbed by the load (W)

$Q_{L} \quad$ reactive power absorbed by the load (Var)

$P_{g} \quad$ grid real power $(\mathrm{W})$

$i_{L f} \quad$ fundamental component of the load current of (A)

$i_{\text {Lnf }} \quad$ non-fundamental component of the load current of (A)

$v_{g} \quad$ grid voltage at the PCC (V)

Manuscript received Aug. 24, 2013; accepted Nov. 7, 2013

Recommended for publication by Associate Editor Woo-Jin Choi.

${ }^{\dagger}$ Corresponding Author: arutchelvi@gmail.com

Tel: +91-431-2473682, Fax: +91-431-2473684, Saranathan College of Eng.

*Dept. of Electrical \& Electronic Eng., J. J. College of Engineering and Technology, Tamil Nadu, India

$\begin{array}{ll}+ & \text { positive sequence } \\ - & \text { negative sequence } \\ 1 & \text { fundamental } \\ \mathrm{n} & \text { non-fundamental } \\ \mathrm{UB} & \text { unbalance } \\ \mathrm{NL} & \text { nonlinear }\end{array}$

\section{INTRODUCTION}

The penetration of distributed generators (DG), based on Photovoltaic (PV) generated electrical energy, into the grid is increasing exponentially. However, it is imperative that the grid integrated power converters applied in PV based DG systems are stochastic in nature. They need careful controller design in order to perform better than the conventional power plants they replace. All three phase AC grids are loaded with nonlinear unbalanced loads. In such an event, it is essential for a PV inverter to feed such a load with a symmetrical three phase voltage source and such grid integration should also fulfill the stringent grid codes during the occurrence of grid faults or the existence of unbalanced and nonlinear loads at the point of common coupling (PCC). PV efficiency is affected 


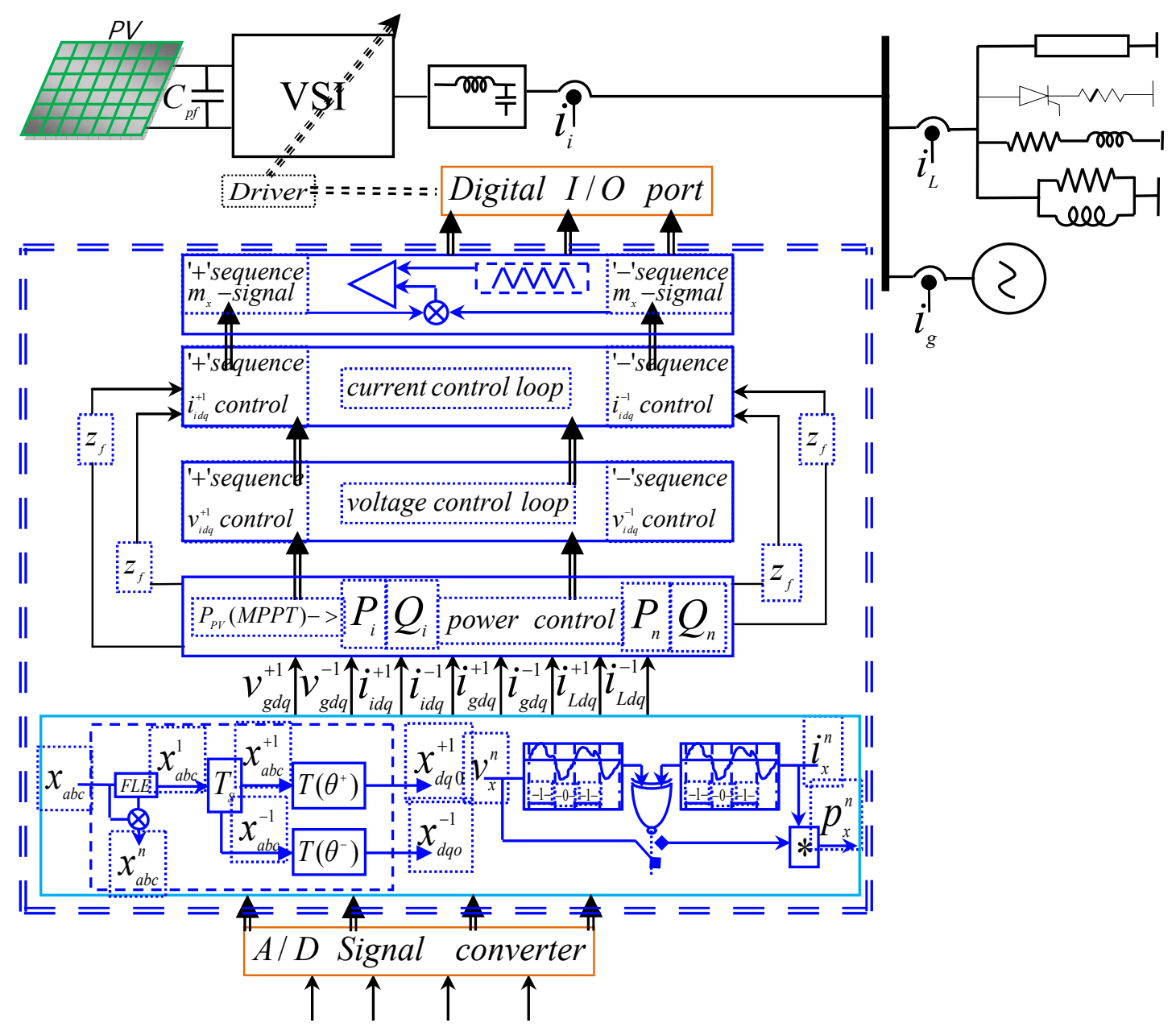

Fig. 1. Block schematic of the proposed scheme.

by an unbalanced grid which introduces pulsating current and voltage ripples [1], [2] to the array. In addition, the voltage fluctuations are introduced by PV sources due to changes in irradiation. The impacts these things have on grid tied systems are discussed in [3]. Power flow control in the grid connected mode and the voltage regulation in the islanding mode for such unbalanced grid conditions are discussed in [4]. However, the impacts of both irradiation and temperature variations in the source side are not considered for the controller design. Although such variations are accounted for in [5], the maximum power utilization of the DG source and the oscillating power components that occur at the grid during unbalanced conditions are not discussed. The active filter configuration for the nonlinear loads incorporated in PV sourced grid connected inverters is presented in [6]. In [7], the DSP based control of the power converters for grid distortion is discussed. A controller for grid inverters during faults in the synchronous reference frame control with separate feed points for both the grid connected and islanding modes of operations is presented in [8]. However, this may be difficult for practical implementation. However in [9], acontrol strategy for the DG sourced grid inverters for nonlinear unbalanced loads with the stationary reference frame in the islanded mode of operation is discussed. SVPWM control of grid connected voltage source converters under unbalanced conditions is dealt with in [10]. [11] shows that the reference current generated for unbalanced grid fault conditions is based on instantaneous conductance variations which are further based on the voltage at the PCC and the power injected by the inverter. However, nonlinear unbalanced load current variations are not incorporated in the reference current generation for the developed controller. In [12], it is shown that the current vector is instantaneously proportional to the voltage vector. Hence, it does not have an orthogonal component in relation to the grid voltage. This holds true only under grid fault conditions and does not support nonlinear unbalanced loads at the PCC. An analysis of the active power control strategies for distributed generation inverters under unbalanced grid faults is discussed in [13].

In this paper, the non-fundamental components are neglected for the reference current generated for the 
controller. However, the reference current generated for the controller design takes into account the PV irradiation variations, the load current, and the current supplied by the inverter and grid current. Furthermore, in this paper, the losses and reactive compensation due to the non-fundamental component are also included in the reference current generation. For the first time, a composite power control (CPC) design based on voltage oriented control (VOC) and direct power control (DPC) in the decoupled double synchronous reference frame (DDSRF) has been presented for a PV sourced grid connected scheme. This scheme also incorporates maximum power extraction from the PV sources, nonlinear-unbalanced compensation and power balance. This is done with the addition of the active filtering effect for the first time. Since the voltage at the PCC is taken as a state variable for the controller design, the same controller can work in both the autonomous and grid connected modes. The proposed controller is implemented and simulated in MATLAB-Simulink-ISE and a Xilinx system generator. The simulation and experimental results are presented in this paper.

\section{FUNCTIONAL BLOCK DIAGRAM OF THE PROPOSED CONTROL SCHEME}

A block schematic of a grid connected PV sourced inverter and a nonlinear unbalanced local load with the proposed control is indicated in Fig.1. The Photovoltaic array sourced inverter is connected to the utility grid through an LC filter and is integrated to the grid at the PCC. The consumer load comprises of loads like linear, nonlinear, dynamic and static loads connected at PCC.

The proposed controller is a composite controller comprising of VOC and DPC to control the firing pulses to the PV sourced inverter. The DPC comprises of a power controller for real and reactive power computation and control. The non-fundamental components of the power signal are separated into discrete voltages and the current signals and are given to the XNOR gate. The output of the $\mathrm{XNOR}$ gate gives the triggering pulses for the estimating real power contributed by the non-fundamental component. The fundamental components of the measured signals are decomposed into positive, negative and zero sequence components. A distributed generator based on a PV fed inverter is interconnected with a three phase, three wire system. Hence it does not inject zero sequence components and is intentionally ignored.

These positive and negative sequence components are transformed into the $\mathrm{dq}$ model in the decoupled double synchronous reference frame. This transformation allows a decoupling of the effect of the negative sequence voltage component on the $d q$ signals detected by the synchronous reference frame rotating with a positive angular speed and vice-versa. This ensures accurate grid synchronization under unbalanced conditions. A three phase synchronous phase lock loop (PLL) block is used to generate a theta value for the abc to dq0 transformation and thereby computes the instantaneous impedance values for $Z_{f n}$ (impedance due to fundamental components) and $Z_{n f}$ (impedance due to non-fundamental components) of the loads from the measured signal. The voltage control block generates the current reference value for the current control block and the output of this block generates the voltage magnitude and angle for the modulating signals for sine pulse width modulation (SPWM). Using these modulating signals, the firing pulses are generated for the VSI. The complete control algorithm is executed through a spartan-6 (XC6SL150T) FPGA chip through analog to digital and digital to analog converters.

\section{Modelling OF THE PROPOSED SCHEME}

Any measured signal is separated into the fundamental and non-fundamental components given by:

$$
f_{a b c}(t)=f_{a b c}^{1}+f_{a b c}^{n}
$$

where $f_{a b c}^{1}$ is the fundamental component of the measured signal and $f_{a b c}^{n}$ is the non-fundamental component. The instantaneous positive and negative sequence components of the generic vector is given by:

$$
f_{a b c}^{1}(t)=f_{a b c}^{+1}+f_{a b c}^{-1}
$$

The positive sequence voltage vector is transformed to the dq double synchronous frame by using Park's transformation and is given by:

$$
\begin{aligned}
& f_{d q}^{+1}=T(\theta) f_{a b c}^{+1} \\
& f_{d q}^{-1}=T(-\theta) f_{a b c}^{-1}
\end{aligned}
$$

These transformations are used in the modeling of grid connected scheme based on a PV array.

\section{A. PV Sourced Grid Connected Inverter}

The voltage equation of a grid connected VSI in the double synchronous frame of reference is written as positive and negative sequence components. The fundamental components of positive and negative sequence inverter current are described as in (5) and (6).

$$
\left[\begin{array}{c}
\frac{d i_{i d}^{+1}}{d t} \\
\frac{d i_{i q}^{+1}}{d t}
\end{array}\right]=\frac{1}{L}\left[\left[\begin{array}{cc}
-R & \omega L \\
-\omega L & -R
\end{array}\right]\left[\begin{array}{c}
i_{i d}^{+1} \\
i_{i q}^{+1}
\end{array}\right]+\left[\begin{array}{c}
v_{i d}^{+1} \\
v_{i q}^{+1}
\end{array}\right]-\left[\begin{array}{c}
v_{g i d}^{+1} \\
v_{g i q}^{+1}
\end{array}\right]\right]
$$




$$
\left[\begin{array}{c}
\frac{d i_{i d}^{-1}}{d t} \\
d i_{i q}^{-1} \\
d t
\end{array}\right]=\frac{1}{L}\left[\left[\begin{array}{cc}
-R & \omega L \\
-\omega L & -R
\end{array}\right]\left[\begin{array}{l}
i_{i d}^{-1} \\
i_{i q}^{-1}
\end{array}\right]+\left[\begin{array}{c}
v_{i d}^{-1} \\
v_{i q}^{-1}
\end{array}\right]-\left[\begin{array}{c}
v_{g i d}^{-1} \\
v_{g i q}^{-1}
\end{array}\right]\right]
$$

The output of the photovoltaic array is coupled to the inverter with appropriate control. The power delivered by the Photovoltaic array parameters dynamically changes due to irradiation and temperature variations [14]. From the equivalent circuit, the PV array and inverter currents are calculated using equations (5)-(9) for regulating the PV sourced inverter power. The state space power control model of the PV sourced grid inverter connected at the PCC under unbalanced condition is indicated as in (10).

$$
\left.\begin{array}{c}
i_{p v}=i_{c}+i_{i p v} \\
i_{p v}=c \frac{d v_{p v}}{d t}+i_{i p v} \\
i_{p v}=c \frac{d v_{p v}}{d t}+\frac{3}{2}\left(k_{m} \cos \theta^{+1} i_{i d}^{+1}+k_{m} \sin \theta^{+1} i_{i q}^{+1}\right) \\
i_{p v}=c \frac{d v_{p v}}{d t}+\frac{3}{2}\left(k_{m} \cos \theta^{-1} i_{i d}^{-1}+k_{m} \sin \theta^{-1} i_{i q}^{-1}\right)
\end{array}\right\}
$$

\section{B. Dynamic Load Modelling (generic dynamic load} model)

Traditional static load models are not suitable as they do not emulate the behaviour of the load. Accurate models of the

\begin{tabular}{|c|c|c|c|c|c|c|}
\hline Mode & 1 & 2 & 3 & 4 & 5 & 6 \\
\hline$a_{d}$ & $1 / \sqrt{3}$ & $-1 / \sqrt{3}$ & $-2 / \sqrt{3}$ & $2 / \sqrt{3}$ & $1 / \sqrt{3}$ & $-1 / \sqrt{3}$ \\
\hline$a_{q}$ & 1 & -1 & 0 & 0 & -1 & 1 \\
\hline
\end{tabular}
power system loads are important to study the dynamic performance of electric power systems. A generic non-linear dynamic load model of the first order as proposed by [15] is used in this paper. $T_{p}$ and $T_{q}$ represent the active and reactive load time recovery constants, respectively. The transient and steady state active and reactive powers as a function of the load voltage are given by:

$$
\begin{aligned}
& P_{L t}=P_{L o}\left(v_{g} / v_{g o}\right)^{\alpha_{t}} P_{L s}=P_{L o}\left(v_{g} / v_{g o}\right)^{\alpha_{S}} \\
& Q_{L t}=Q_{L o}\left(v_{g} / v_{g o}\right)^{\beta_{t}} Q_{L s}=Q_{L o}\left(v_{g} / v_{g o}\right)^{\beta_{S}}
\end{aligned}
$$

\section{TABLE I}

The VALues OF $A_{D}$ AND $A_{Q}$

The subscript " 0 " denotes the previous state of the change and $P_{L s}, P_{L t}, Q_{L s}, Q_{L t}$ are the steady state and transient active and reactive powers of the load. $\alpha_{s} \alpha_{t}$ and $\beta_{s} \beta_{t}$ represent the steady state and the transient active and reactive load voltage dependences and they are determined using [16]:

$$
\begin{aligned}
& \alpha_{t}=\frac{\log \left(P_{L} / P_{L 0}\right)}{\log \left(v_{g} / v_{0}\right)} \\
& \beta_{t}=\frac{\log \left(Q_{L} / Q_{L 0}\right)}{\log \left(v_{g} / v_{0}\right)}
\end{aligned}
$$

\section{Non-Linear Load Model (three phase rectifier load model)}

A nonlinear load model comprising of a three-phase diode rectifier feeding an R-L load is modelled in the $d q$ reference frame for analysis. The rms value of the input currents $\left(i_{L 2 a}\right.$, $i_{L 2 b}$, and $i_{L 2 c}$ ) of the three-phase diode rectifier in the $d q$ reference frame are given by:

$$
\left[\begin{array}{l}
i_{L 2 d} \\
i_{L 2 q}
\end{array}\right]=\left(\begin{array}{l}
a_{d} \\
a_{q}
\end{array}\right) \quad i_{d c}
$$

where $i_{L 2 d}$ and $i_{L 2 q}$ are the $d$ and $q$ axes of the nonlinear load current. The current drawn by the three phase rectifier is directly converted from the $a b c$ to $d q o$ frame by using equation (17). In this equation the values of $a_{d}$ and $a_{q}$ are changed at every $60^{\circ}$ of one cycle as shown in Table I.

\section{Unbalanced Nonlinear Load Model}

A two arm bridge rectifier is connected between the two phases with a DC RL load to create an unbalance at the PCC. The current drawn by the load in the dq frame is obtained as in equations (18) and (19).

$$
\begin{aligned}
& i_{L_{q}}=\sqrt{\frac{2}{3}}\left[\begin{array}{l}
\sin \theta \frac{3}{\pi} i_{L} \theta(t)-\frac{2}{\pi} i_{L} \theta(t) \\
\sin \left(\theta-\frac{2 \pi}{3}\right)-\frac{-3}{\pi} i_{L} \theta(t) \sin \left(\theta+\frac{2 \pi}{3}\right)
\end{array}\right] \\
& i_{L d}=\sqrt{\frac{2}{3}}\left[\begin{array}{l}
\cos \theta \frac{3}{\pi} i_{L} \theta(t)-\frac{2}{\pi} i_{L} \theta(t) \\
\cos \left(\theta-\frac{2 \pi}{3}\right)-\frac{-3}{\pi} i_{L} \theta(t) \cos \left(\theta+\frac{2 \pi}{3}\right)
\end{array}\right]
\end{aligned}
$$




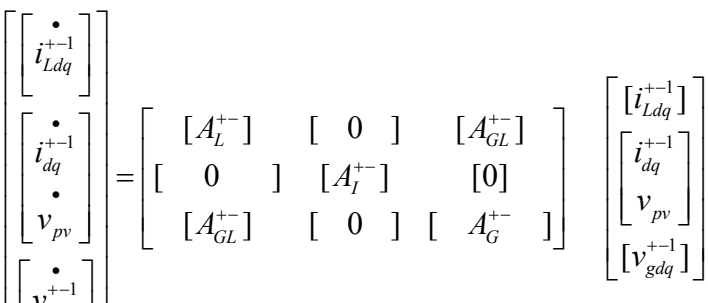

$$
\begin{aligned}
& +\left[\begin{array}{c}
{\left[B_{w}^{+-}\right]} \\
{\left[\begin{array}{cc}
{[} & B_{I}^{+-}
\end{array}\right]} \\
{\left[\begin{array}{ll}
{[} & 0
\end{array}\right]}
\end{array}\right] \quad\left[U^{+-}\right]
\end{aligned}
$$

The proposed $d q$ model of the grid integrated PV distributed system using equations (1)-(19) is indicated in Fig. 2 (a), (b), (c), and (d), and the state equation is indicated in equation (20).

\section{DESIGN AND DEVELOPMENT OF THE COMPOSITE CONTROLLER}

The composite controller, which combines the advantages of DPC and VOC is designed for the grid connected PV sourced inverter for sharing nonlinear unbalanced loads at the PCC.

Therefore, the proposed controller ensures a balanced current exchange with the PCC. In addition, the current fed by the inverter is a smooth sine wave with real power oscillations completely removing and suppressing the reactive power oscillations. Moreover, the controller simultaneously ensures that the maximum power is extracted from the PV source even in varying irradiation. Furthermore, the active filtering effect is incorporated into the controller design and is evident from the increased effective apparent power supplied by the inverter which complies with the IEEE1459-2010 standard.

\section{A. The Voltage and Current Control Block}

The voltage and current control block estimates the voltage and current references from the inverter. The current references are estimated in both the positive and negative sequences separately from the inverter using equation (10). The voltage control block gets the input reference signal from the power control block. The input to the current control block is obtained from the voltage control block and from the power control block through the filter impedance. The output of the current controller is fed to set the pulse duty ratio for PWM generation and is illustrated in Fig. 3 and Fig. 4.

\section{B. Power Control Block}

In the development of the proposed CPC strategy, the hysteresis controller in the DPC scheme is eliminated and the current reference for the current controller is obtained by utilizing the separated fundamental components of the power with the symmetrical component transformation to meet the instantaneous power demand at the PCC. The basic power

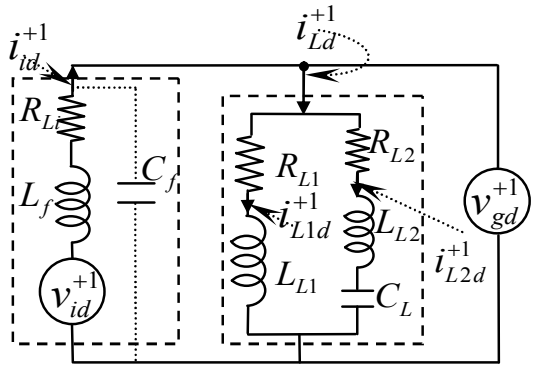

(a)

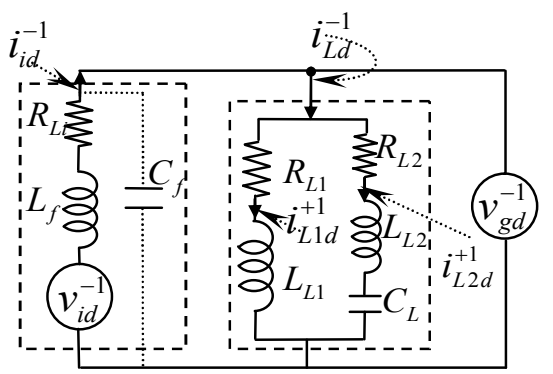

(b)

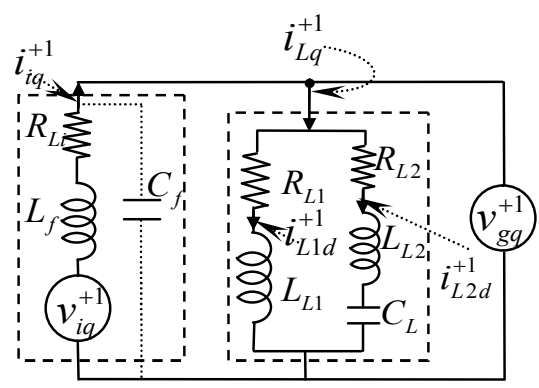

(c)

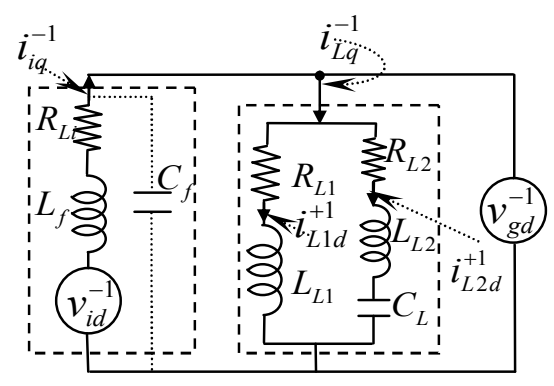

(d)

Fig. 2. (a), (c) \& (b), (d) “+” and "-” sequence dq axes model of grid integrated PV inverter.

$$
P_{i}=P_{L} \pm P_{g}
$$

balance equation for a grid integrated DG based on PV array is indicated in (21).

Under an unbalanced load at the grid, the current injected at the grid is neither sinusoidal nor balanced. Therefore, for the controller design, the instantaneous active and reactive powers comprising of average values of the instantaneous active and reactive powers and the oscillating powers of these 


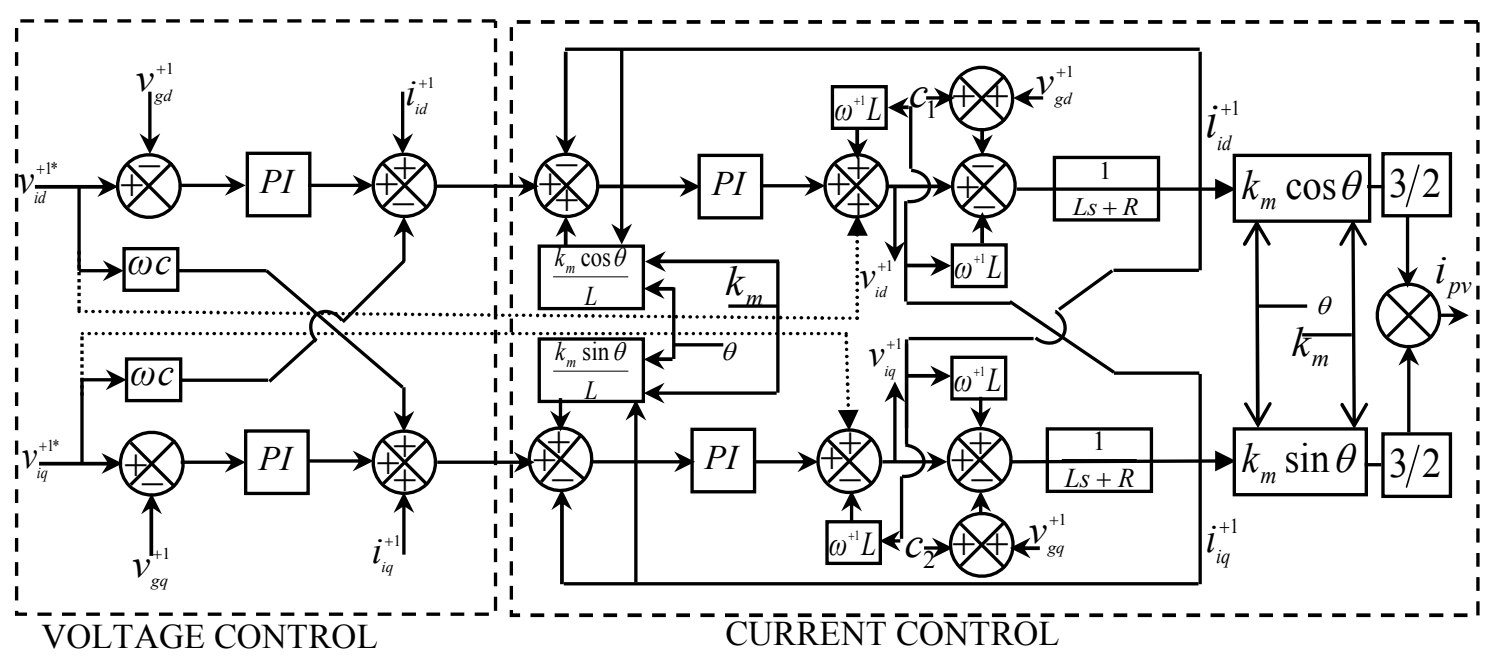

Fig. 3. "+"sequence Voltage and current controller.

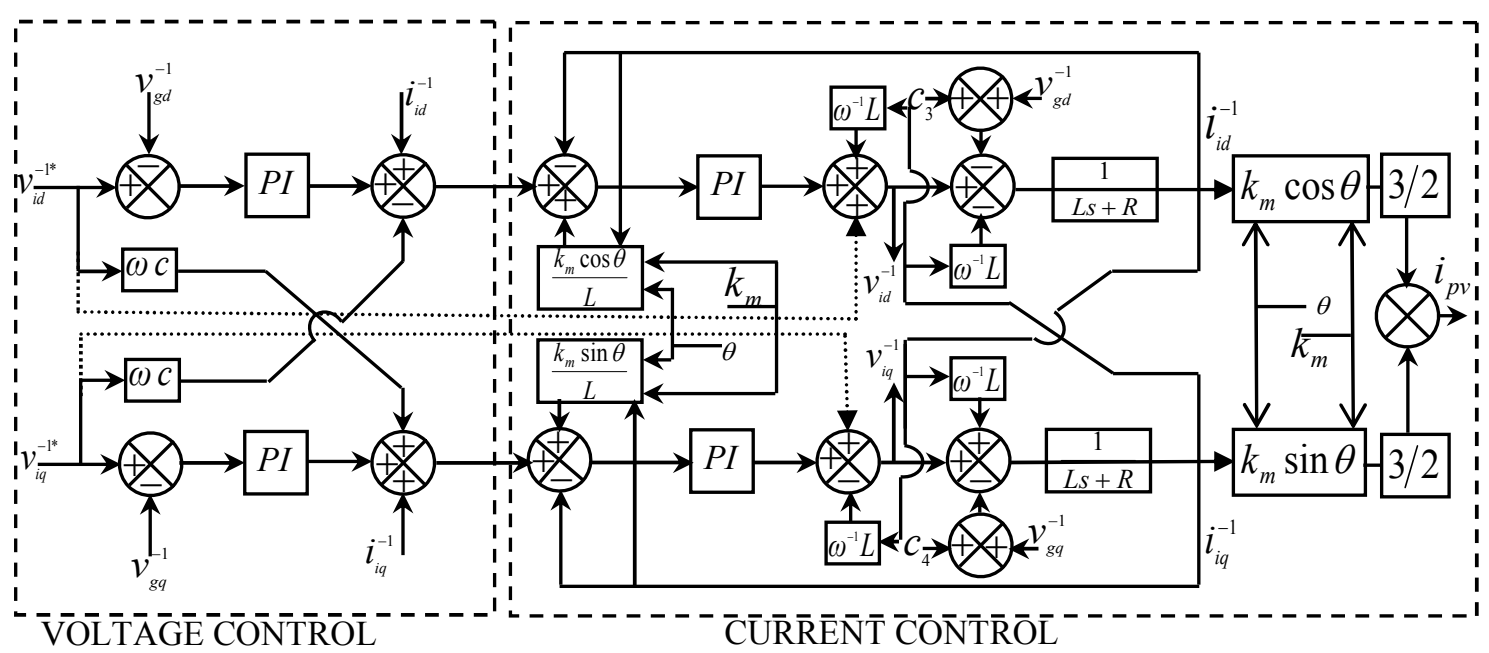

Fig. 4. “-”sequence Voltage and current controller.

instantaneous powers needs to be taken into consideration and are indicated in the following Matrix equation (22).

$$
\left[\begin{array}{c}
P_{y}^{0} \\
P_{y}^{1} \\
P_{y}^{2} \\
Q_{y}^{0}
\end{array}\right]=(3 / 2)\left[\begin{array}{cccc}
v_{y d}^{+1} & v_{y q}^{+1} & v_{y d}^{-1} & v_{y q}^{-1} \\
v_{y q}^{-1} & -v_{y d}^{-1} & -v_{y q}^{+1} & v_{y d}^{+1} \\
v_{y d}^{-1} & v_{y d}^{-1} & v_{y d}^{+1} & v_{y q}^{+1} \\
v_{y q}^{+1} & -v_{y d}^{-1} & v_{y q}^{-1} & v_{y d}^{-1}
\end{array}\right]\left[\begin{array}{c}
i_{y d}^{+1} \\
i_{y q}^{+1} \\
i_{y d}^{-1} \\
i_{y d}^{-1}
\end{array}\right]
$$

In (22), $P^{0}, Q^{0}$ are the average values of the instantaneous active and reactive powers. $P^{l}, P^{2}$ represent the magnitude of the oscillating terms of the real power which results from the interaction of the voltage and current components of different frequencies or sequences.

The subscript ' $y$ ' is a generic term which represents the inverter or load. Expressing (23) as in (22):

$$
\left(P_{i}^{o}+P_{i}^{1}+P_{i}^{2}\right)=\left(P_{L}^{0}+P_{L}^{1}+P_{L}^{2}\right)+P_{g}+P^{n}
$$

$$
\begin{aligned}
P_{i}^{0} & =P_{L}^{0} \pm P_{g}^{0} \\
P_{i}^{1}+P_{i}^{2} & =P_{L}^{1}+P_{L}^{2}+P^{n}
\end{aligned}
$$

And the reactive power is expressed as (26).

$$
Q_{i}=\left(Q_{L}+Q_{g}+Q^{n}\right)
$$

It is necessary to calculate the currents to be supplied by the inverter that will give rise to certain values of real and reactive powers while also cancelling out the real and reactive power oscillating terms under unbalanced conditions. These power requirements at the PCC can be fulfilled by finding current references in the positive and negative sequence in the DDSRF as in (2) and used in (23) to generate reference current as indicated in (27-30). The voltage control block gets the input reference signal from the power control block. The input to the current control block is obtained from the voltage control block and from the power control block through the filter impedance. 


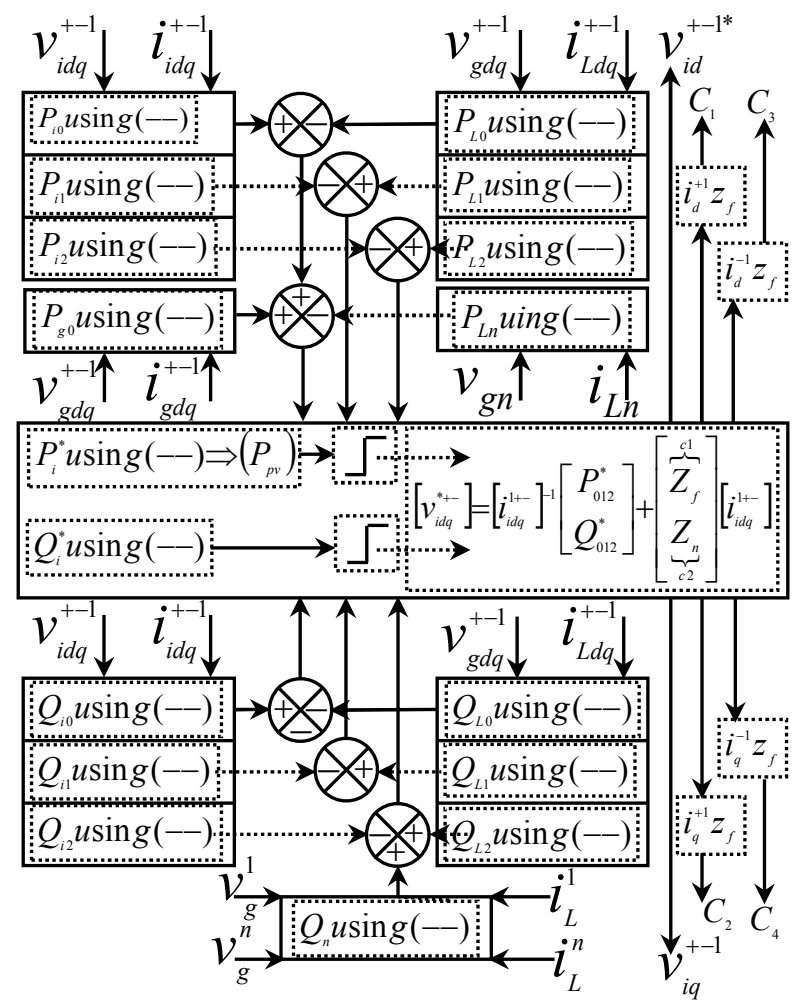

Fig. 5. Power controller block.

$$
\begin{aligned}
& i_{i q}^{+^{*}}=\left[\begin{array}{c}
\frac{\left(v_{g q}^{+}\right)^{2}}{\left(v_{g q}^{+}\right)^{2}-\left(v_{g q}^{-}\right)^{2}}\left[i_{L q}^{+}-i_{g q}^{+}\right] \\
-\frac{\left(v_{g q}^{-}\right)^{2}}{\left(v_{g q}^{+}\right)^{2}-\left(v_{g q}^{-}\right)^{2}}\left[i_{L q}^{+}-i_{g q}^{+}\right]
\end{array}\right] \\
& i_{i d}^{+^{*}}=\left[\begin{array}{l}
\frac{\left(v_{g q}^{+}\right)^{2}}{\left(v_{g q}^{+}\right)^{2}-\left(v_{g q}^{-}\right)^{2}}\left[i_{L d}^{+}+i_{g d}^{+}\right]+\frac{2 v_{g q}^{+} v_{g q}^{-}}{\left(v_{g q}^{+}\right)^{2}+\left(v_{g q}^{-}\right)^{2}} i_{g d}^{-} \\
+\frac{\left(v_{g q}^{-}\right)^{2}}{\left(v_{g q}^{+}\right)^{2}+\left(v_{g q}^{-}\right)^{2}}\left[i_{L q}^{+}-i_{g q}^{+}\right]
\end{array}\right] \\
& i_{i q}^{+*}=\left[\begin{array}{c}
\frac{\left(v_{g q}^{+}\right)^{2}}{\left(v_{g q}^{+}\right)^{2}-\left(v_{g q}^{-}\right)^{2}}\left[i_{L q}^{-}-i_{g q}^{-}\right] \\
-\frac{\left(v_{g q}^{-}\right)^{2}}{\left(v_{g q}^{+}\right)^{2}-\left(v_{g q}^{-}\right)^{2}}\left[i_{L q}^{-}-i_{g q}^{-}\right]
\end{array}\right] \\
& i_{i d}^{-*}=\left[\begin{array}{l}
\frac{\left(v_{g q}^{+}\right)^{2}}{\left(v_{g q}^{+}\right)^{2}-\left(v_{g q}^{-}\right)^{2}}\left[i_{L d}^{-}+i_{g d}^{-}\right]+\frac{2 v_{g q}^{+} v_{g q}^{-}}{\left(v_{g q}^{+}\right)^{2}+\left(v_{g q}^{-}\right)^{2}} i_{g d}^{+} \\
+\frac{\left(v_{g q}^{-}\right)^{2}}{\left(v_{g q}^{+}\right)^{2}+\left(v_{g q}^{-}\right)^{2}}\left[i_{L d}^{-}+i_{g d}^{-}\right]
\end{array}\right]
\end{aligned}
$$

Impacts created by the unbalanced nonlinear currents in the filter drop are nullified by adding the required impedance.
The resultant regulated PV inverter terminal voltage is indicated in (31).

$$
\left[v_{i d q}^{+-1}\right]=\left[i_{i d q}^{+-1}\right]^{-1}\left[\begin{array}{c}
P_{i 012}^{*} \\
Q_{i}^{*}
\end{array}\right]+\left[\left(Z^{+-1}+Z^{n}\right)\right]\left[i_{i d q}^{+-1}\right]
$$

Based on equations (22) - (31), the developed power control block is represented as in Fig 5.

The output of the current controller is given to the sinusoidal pulse width modulation (SPWM) block to generate the firing pulses to the inverter. Additionally, the function of the Active Power Filter (APF) is added to the controller structure. The APF compensates the reactive power demand due to the non-fundamental components with the proper estimation of the reference current for the current control loop.

\section{Working of the Proposed Composite Controller}

The structure of the detailed model of the proposed composite controller developed in section IV is given in Fig 5.

The load currents and voltages at the PCC are measured and the measured parameters are separated into its $d q$ sequence components as indicated in the generic equations (1)-(4). The average and oscillating powers drawn by the unbalanced load are calculated using (23). Simultaneously, the powers injected by the DG source and the power exchanged by the grid are also computed. The proposed power controller separately estimates the average and oscillating power mismatch values with respect to the instantaneous power availability of the PV source (24)-(26). The power controller generates the inverter output voltage and current reference values with filter drop impacts. It then sends these voltage and current references to the respective control blocks. The current controller gives the $d q$ positive and negative values of the inverter output reference voltage $\left(v_{i}^{+}, v_{i}^{-}\right)$. The magnitudes and angles of both the modulating positive and negative signals that are obtained as voltage references are combined to generate pulses for the VSI.

The proposed controller has been tested for three phase, three wire unbalanced RL loads, unbalanced nonlinear loads connected between two phases, and the simultaneous switching of unbalanced RL loads and nonlinear loads at PCC. The working of the proposed controller and the operating modes of the proposed controller are indicated by the phasor diagram representation in Fig $6 \mathrm{a}$ and $6 \mathrm{~b}$.

The phasor diagram depicts the maximum instantaneous flow of currents and the PCC voltage that can be injected at the PCC by the proposed controller in the grid connected and island modes of operation. The phasor diagram also gives the controllable zones of the active and reactive set points which are limited by the ratings of the power converter, the unbalanced nonlinear load conditions, the control parameters and the islanding mode of operation. 


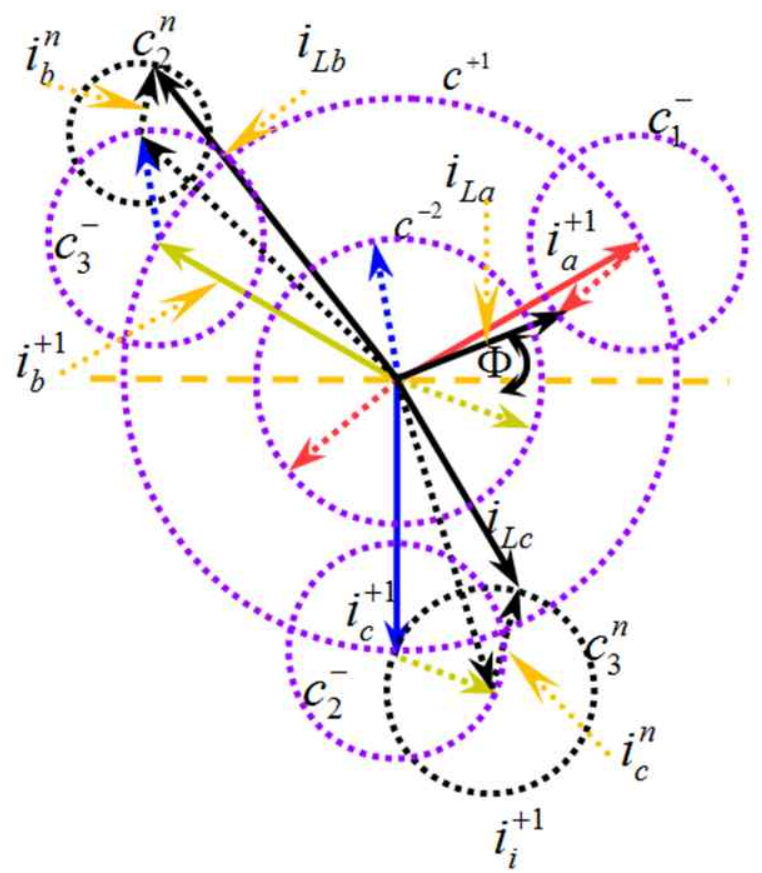

(a)

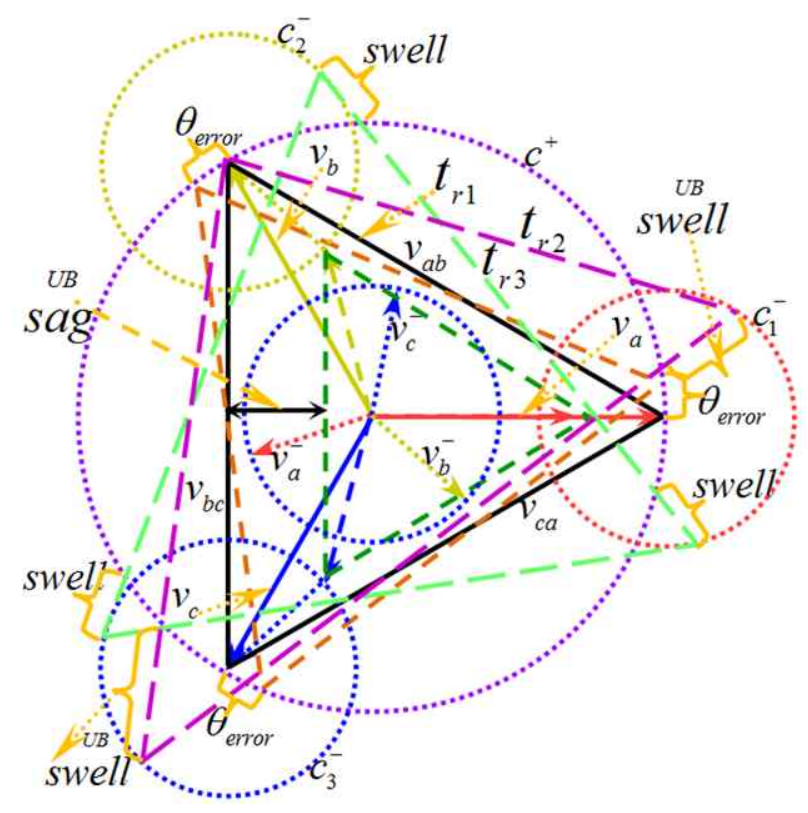

Fig. 6. (a) Phasor representation of grid connected mode operation. (b) Phasor representation of isolated mode operation.

The positive, negative and nonlinear current components are denoted by $a^{+} b^{+} c^{+}, a^{-} b^{-} c^{-}$and $a^{n} b^{n} c^{n}$, respectively. All of the positive and negative current components are deviated at an angle $\Phi^{+}, \Phi^{-}$from the reference axis. In the grid connected mode, when an unbalanced nonlinear load is added between phases $\mathrm{b}$ and $\mathrm{c}$, the nonlinear unbalanced load current $i_{L c}$ is compensated by adding the current vectors $b^{+}, c^{-}$, and $b^{n}$. Similarly the other two phase currents $i_{L b}$ and $i_{L a}$ are compensated. The circles $\mathrm{C}^{+1}$ and $C^{2}$ denote the amount of maximum positive sequence and negative sequence current

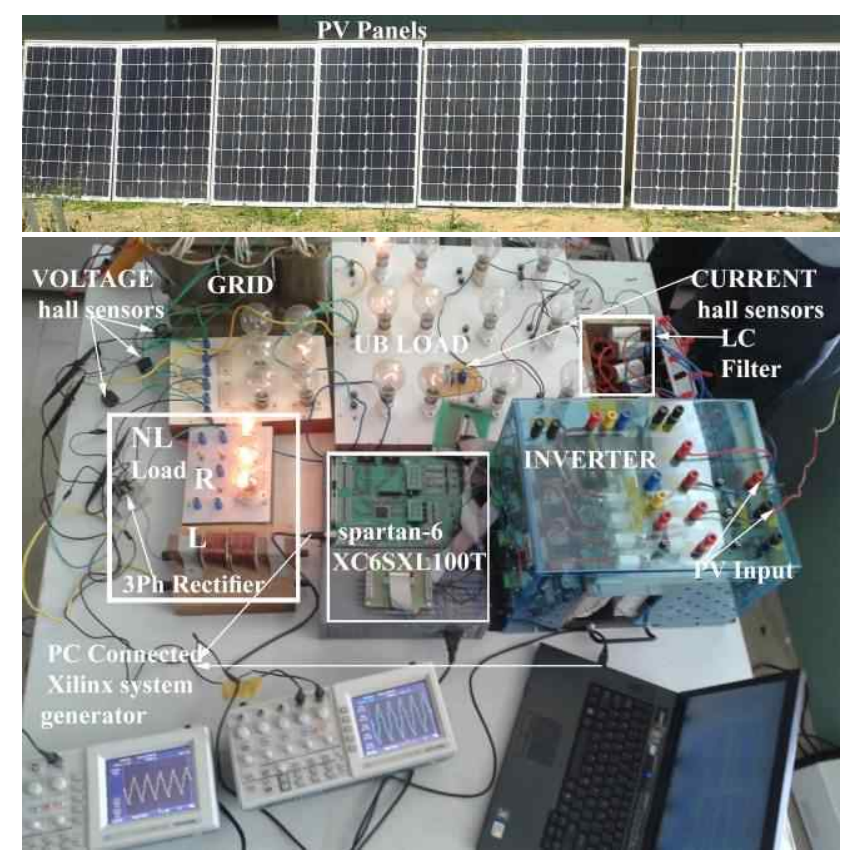

Fig. 7. Experimental setup for proposed scheme.

delivered by the inverter simultaneously. However, if circle $C^{+2}$ exceeds circle $C^{+1}$ the inverter injects more reactive power than real power. Thus, the inverter acts as a reactive power compensator and the proposed controller is designed to prevent this violation.

$C^{n}$ is the current loci of the nonlinear current. The PV sourced inverter is capable of supplying the required current as long as the area of $C^{n}$ is within $C^{+1}$ and $C^{-2}$. The line voltage triangle under the normal steady state operating condition is indicated by $\operatorname{tr}_{1} . \mathrm{t}_{\mathrm{r} 2}$ and $\operatorname{tr}_{3}$. This gives information about the balanced and unbalanced voltage swells during the islanded mode of operation. Voltage sags occurs during faults in the islanded mode. Subsequently, the operating point varies because of the changes in the voltage magnitude and angle and attempts to shift the line voltage triangle to $t_{\mathrm{r} 2}$. However, the proposed CPC retains the original $t_{r 1}$ to nullify the effect of sags. In the islanded mode of operation, when customer demand is reduced suddenly, the voltage triangle $t_{r 1}$ losses angle $\theta$ hence voltage swells occurs in one phase and the other two phases are affected by the $\theta$ error and represented as $\mathrm{C}^{-}$.

This shifts voltage triangle $t_{r 1}$ to $t_{r 2}$. The proposed control attempts to nullify this change in $\theta$ subjected to the constraint that $\mathrm{C}^{+}$does not exceed $\mathrm{C}^{-}$.

\section{IMPLEMENTATION AND ANALYSIS OF THE PROPOSED PV BASED GRID CONNECTED SCHEME}

Simulations and hardware implementation have been carried out using the developed state space model in the decoupled double synchronous reference frame using 


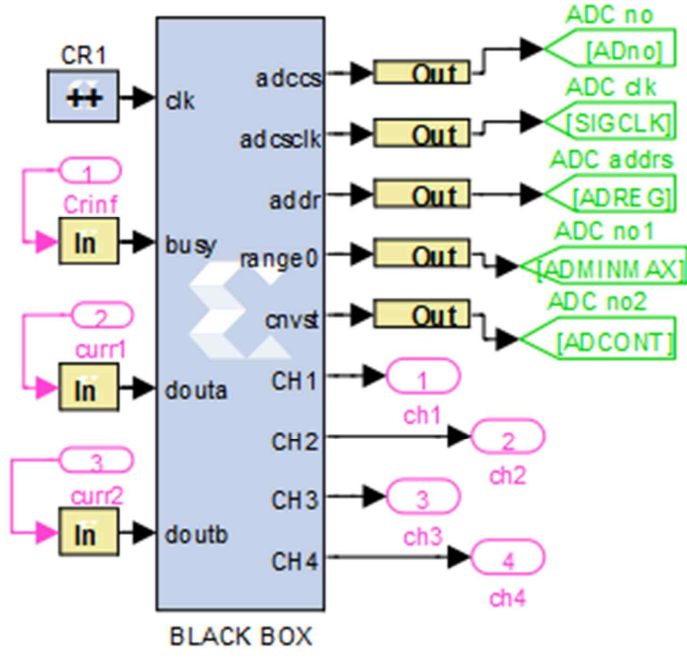

(a)

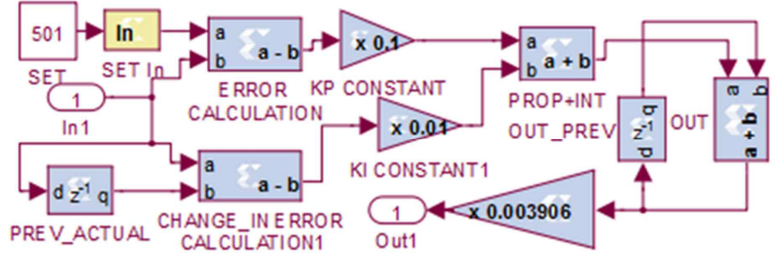

QUANTIZATION_FACTOR

(b)

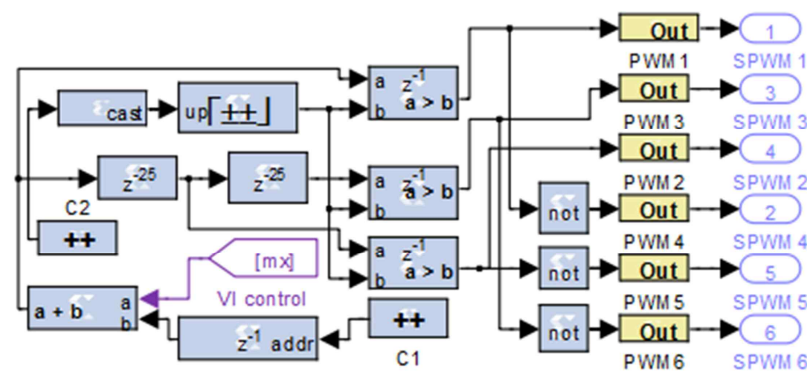

(c)

Fig. 8. (a) Data acquisition block. (b) PI control in FPGA. (c) SPWM.

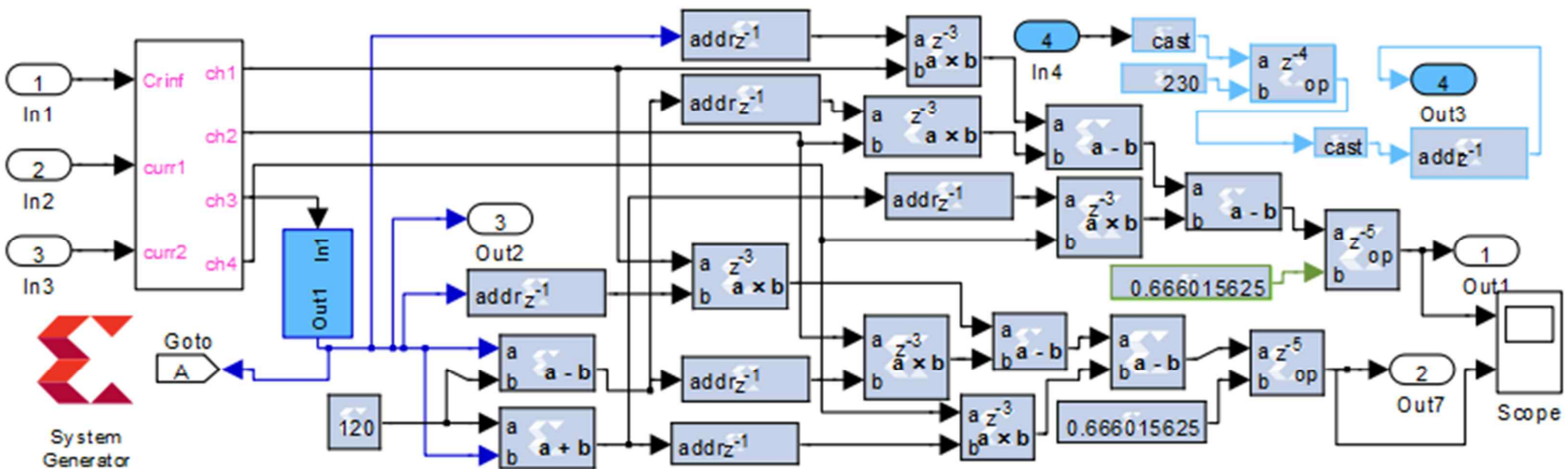

Fig. 9. Voltage and current control using spartan-6 XC6SXL100T.

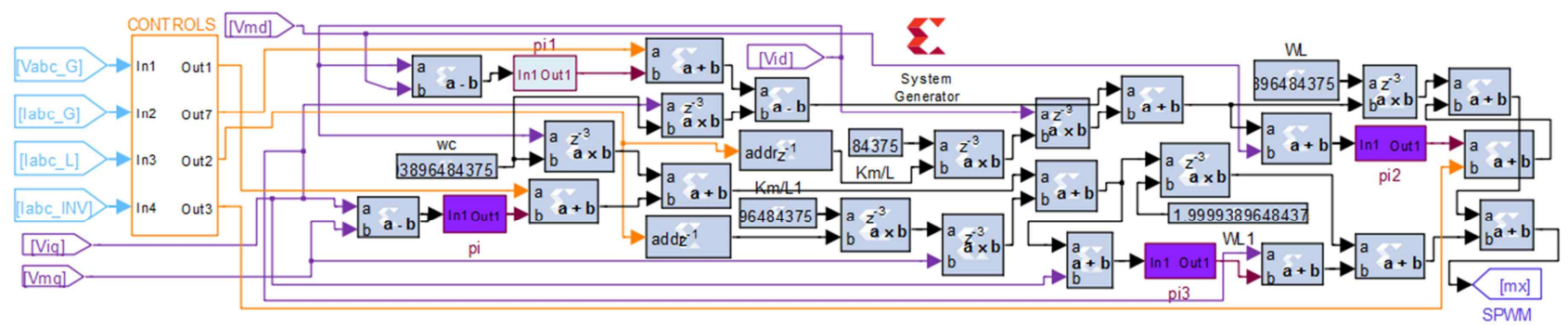

Fig. 10. Power controller using spartan-6 XC6SXL100T.

MATLAB-Simulink-ISE and a Xilinx system generator. The experimental set up for the proposed scheme is indicated in Fig. 7.

The simulation parameters of the PV rating, irradiation, and load ratings are indicated in Table II. A panel of $1 \mathrm{kWp}$ is chosen for the experimental set up. A DC link capacitor of 3300 micro Farad, $450 \mathrm{~V}$ is used. A Semikron inverter
(SKM100GB12V) with an IGBT of rating 1200V, 100A with a SKYPER 32R driver board at a switching frequency of $20 \mathrm{kHz}$ is employed. The voltage and current signals are measured by means of hall sensors (LTS25NP). The data acquisition board contains eight slots each comprising of voltage and current Hall sensors and a A/D converter (AD7366, dual channel, 12bit bipolar) with an AD8022 serial buffer. These signals 
are fed to the FPGA through the gate way options and the received signal is separated into fundamental and non-fundamental components simultaneously by using a multichannel FIR filter in DSP48A slices in a spartan-6 XC6SXL100T (with $20 \mathrm{MHz}$ clock). The fundamental $a b c$ components are converted into the $d q 0$ reference frame using the constructed Clark transformation block as indicated by vector manipulation parallel through six DSP48A slices as shown in Fig. 8(a) and 8(b).

Again this signal is transferred to the power control block which is developed as indicated in equation (31) for generating the reference voltage and current values for the respective positive and negative sequence control loops which are shown in Fig. 9.

The FPGA implementation of the power controller block indicated in Fig. 5 is shown in Fig. 10. The output of the current control loop generates the magnitude and angle values of the modulating signal which are then fed to the black box model of the PWM generation block as shown in Fig. 8(c).

The reset time of the counter is set in accordance with the angle of the modulating signal obtained from the current control block. The output level of these PWM signals is shifted from $3.3 \mathrm{~V}$ to $15 \mathrm{~V}$ using a high voltage level shifting IC CD45045. A programmable delay time is included in the designed XC6SXL100T IC. The delay time controller generates the gating signal to the toggle switches. The delay time is calculated based on the magnitude of the modulating signal.

The proposed scheme is tested with a RL load of $700 \mathrm{~W}$ and a three phase bridge rectifier module VS-26MT100 of 300W acting as a nonlinear load.

Case i: Three phase, three wire, unbalanced RL load at the PCC with a constant irradiation at the PV source.

When a three phase, three wire, unbalanced RL load is added at the PCC at $\mathrm{t}=1 \mathrm{~s}$, the oscillographic waveforms of the unbalanced current drawn by the load are indicated in Fig. 11(a) and the simulated waveforms for the same are indicated in Fig. 11(b).

A slight deviation is observed in the experimental load current due to a slight mismatch in the designed and simulated inductor values. The same inverter current injected at the PCC with the DPC scheme is indicated in Fig. 12. The experimental waveforms of the current delivered by the inverter with the proposed CPC are indicated in Fig. 13(a) and the simulated results for the same are indicated in Fig. 13(b). It is evident that the load current unbalance is reflected in the inverter current by the proposed CPC scheme. Hence, the unbalance power required by the load is contributed by the inverter. However, in the DPC scheme, the inverter current is almost balanced. Hence, a distorted current flows into the grid as indicated in Fig. 14. In addition, it is evident that the performance of the grid is affected by the
TABLE II

The Simulation Parameters of the PV Rating, Irradiation, AND LOAD RATINGS

\begin{tabular}{|c|c|c|c|}
\hline Modules & Parameters & Rating & \\
\hline \multirow{7}{*}{ PV module } & $\begin{array}{l}\text { Maximum } \\
\text { power }\end{array}$ & $80 \mathrm{~W}$ & \\
\hline & $\begin{array}{l}\text { Open Circuit } \\
\text { Voltage }\left(\mathrm{V}_{\mathrm{oc}}\right)\end{array}$ & $21.29 \mathrm{~V}$ & \\
\hline & $\begin{array}{l}\text { Short Circuit } \\
\text { Current }\left(\mathrm{I}_{\mathrm{sc}}\right)\end{array}$ & $4.72 \mathrm{~A}$ & \\
\hline & $\begin{array}{l}\text { No of Strings } \\
\text { in parallel }\end{array}$ & 11 & \\
\hline & $\begin{array}{l}\text { No of Strings } \\
\text { in series }\end{array}$ & 30 & \\
\hline & $\begin{array}{l}\text { Variation of } \\
\text { Irradiation }\end{array}$ & $\begin{array}{l}0.47 \mathrm{~W} / \mathrm{n} \\
\text { onwards }\end{array}$ & \\
\hline & Temperature & $30^{\circ} \mathrm{C}$ & \\
\hline $\begin{array}{l}\text { Three phase } \\
\text { inverter }\end{array}$ & IGBT module & $\begin{array}{l}1200 \mathrm{~V}, \\
\text { SKM100 }\end{array}$ & $\begin{array}{l}0 \mathrm{~A} \\
\mathrm{~B} 12 \mathrm{~V}\end{array}$ \\
\hline Grid & \multicolumn{3}{|c|}{$3 \phi, 281.92 V_{\text {Lrms }}, 50 \mathrm{~Hz}$} \\
\hline Dynamic Load & \multicolumn{3}{|c|}{$\begin{array}{l}7-11.2 \mathrm{~kW}, 0.5-1.5 \mathrm{kVar} \\
\mathrm{R}=36.33 \Omega, \mathrm{L}=18.61 \mathrm{H}\end{array}$} \\
\hline Nonlinear load & \multicolumn{3}{|c|}{$\begin{array}{l}2.5 \mathrm{~kW}, 2 \text { leg rectifier load } \\
\mathrm{R}=98.52 \Omega, \mathrm{L}=38.93 \mathrm{H}\end{array}$} \\
\hline Power Diode & \multicolumn{3}{|l|}{$1000 \mathrm{~V}, 25 \mathrm{~A}$} \\
\hline
\end{tabular}

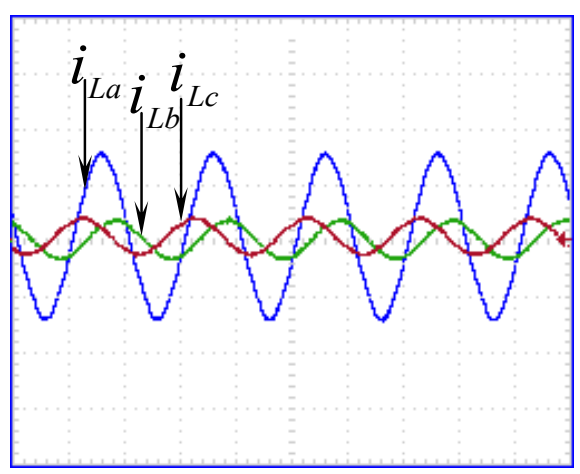

(a)

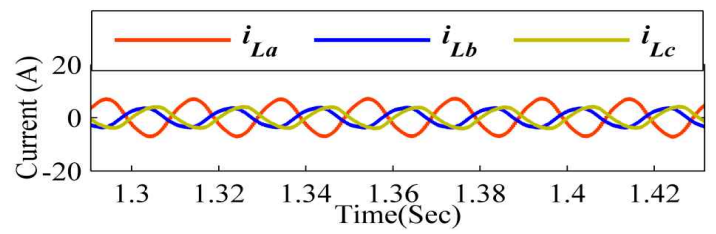

(b)

Fig. 11. Current drawn by RL Unbalance Load at PCC. (a) Simulated (10A/div; 20ms/div). (b) Experimental(2A/div; $20 \mathrm{~ms} / \mathrm{div})$.

system unbalance current by the DPC. Furthermore, the average power delivered by $\mathrm{PV}$ sourced inverter is also reduced and the excess power demand is drawn from the grid. The simulated and experimental waveforms of the current delivered to the grid with the proposed CPC control are indicated in Fig. 15(a) and 15(b). The current delivered to the grid is balanced and further, the similarity between the 


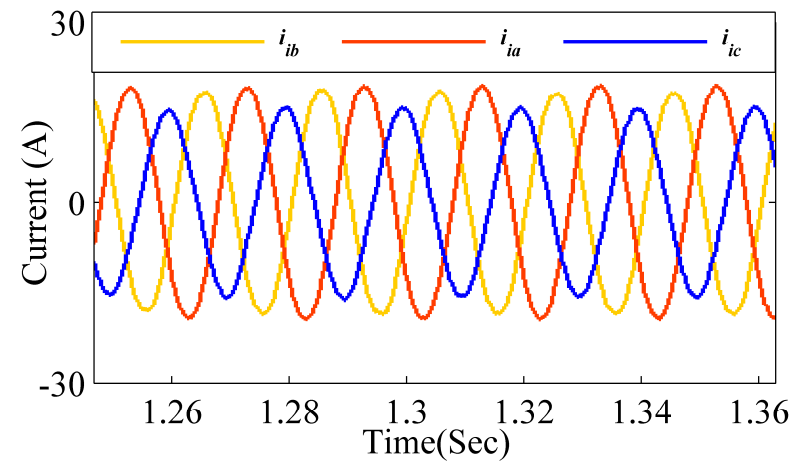

Fig. 12. Current injected by PV sourced inverter at PCC with DPC.

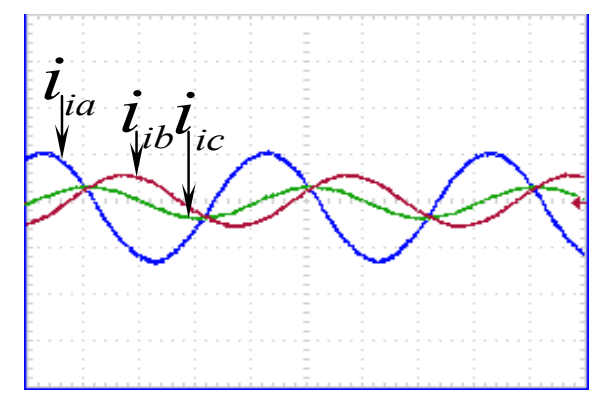

(a)

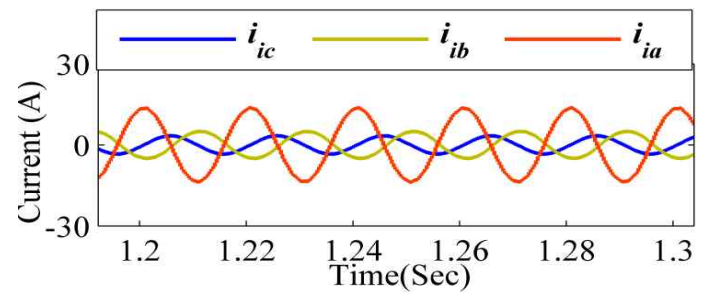

(b)

Fig. 13. Current injected by PV sourced inverter at PCC with CPC (a) Experimental $(2.5 \mathrm{~A} / \mathrm{div} ; 20 \mathrm{~ms} / \mathrm{div})$. (b) Simulated $(10 \mathrm{~A} / \mathrm{div} ; 20 \mathrm{~ms} / \mathrm{div})$

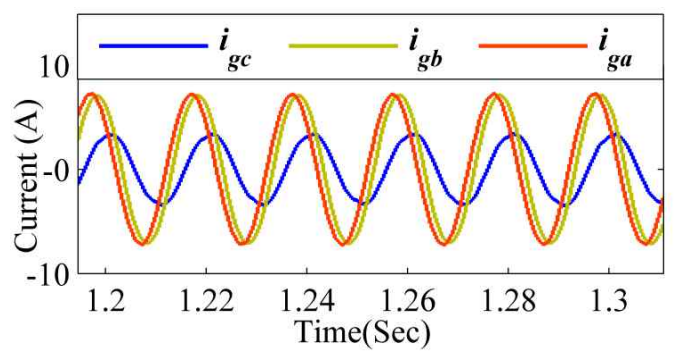

Fig. 14. Current exchanged from PCC to grid with DPC scheme .

experimental and simulated grid currents indicates the validity of the grid model taken up for the simulation.

Case ii: Nonlinear unbalanced RL load at the PCC with constant irradiation at the source.

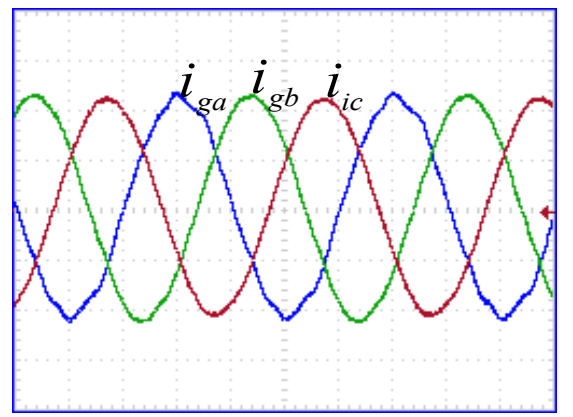

(a)

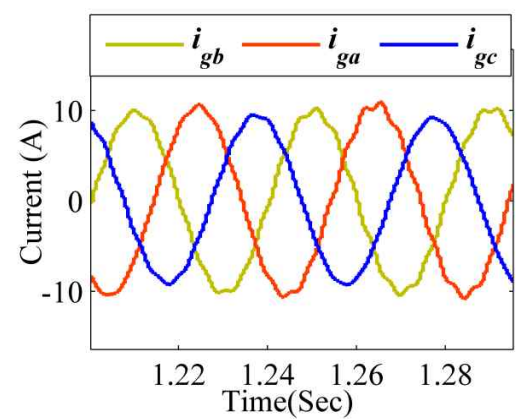

(b)

Fig. 15. Current exchanged from PCC to grid with $\mathrm{CPC}$ scheme, (a) Simulated (10A/div; 20ms/div). (b) Experimental(.5A/div; $20 \mathrm{~ms} / \mathrm{div})$

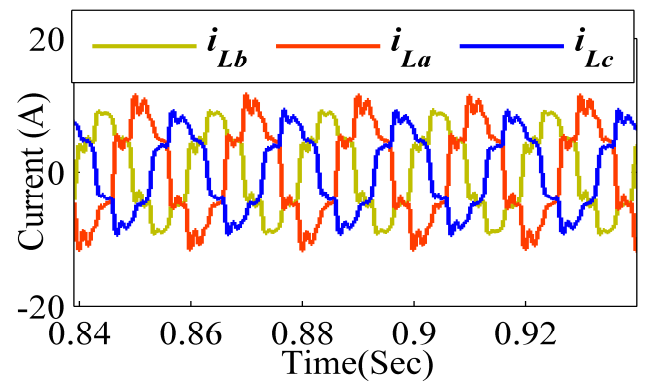

(a)

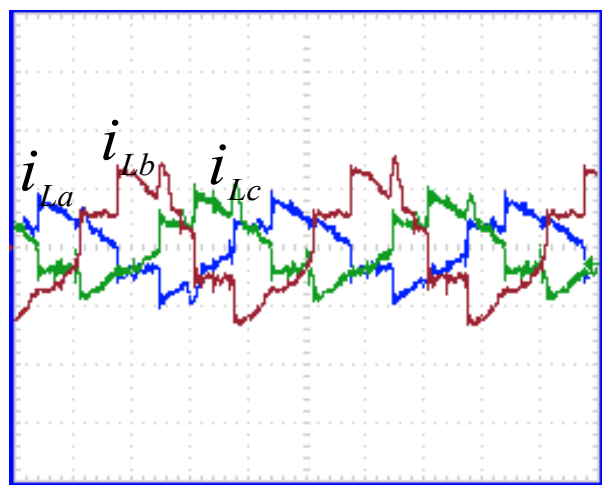

(b)

Fig. 16 Current drawn by Nonlinear Unbalance Load at PCC (a) Simulated (10A/div; 20ms/div). (b) Experimental(2A/div; $20 \mathrm{~ms} / \mathrm{div})$. 


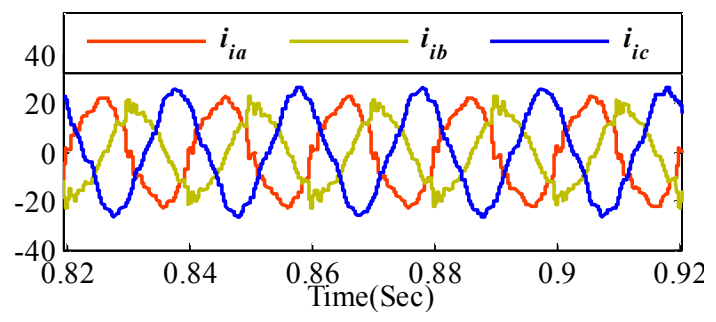

Fig. 17. Current injected by PV sourced inverter at PCC with DPC.

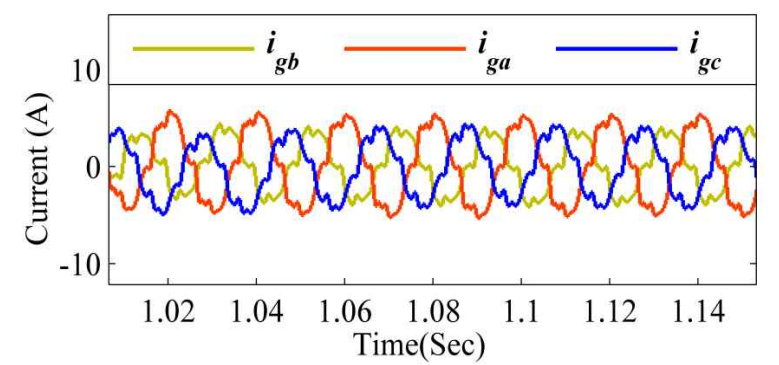

Fig. 18. Nonlinear current exchanged from PCC to grid with DPC scheme.

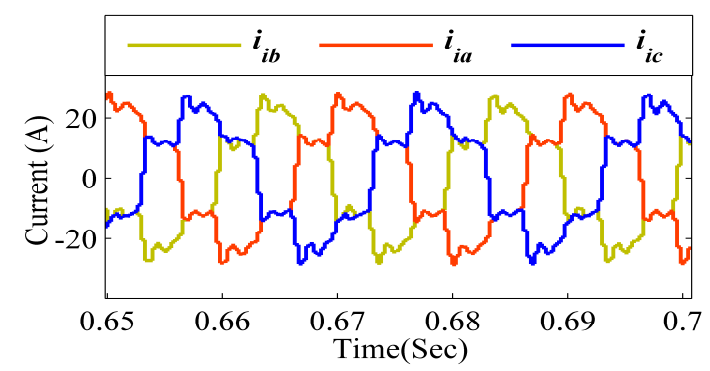

(a)

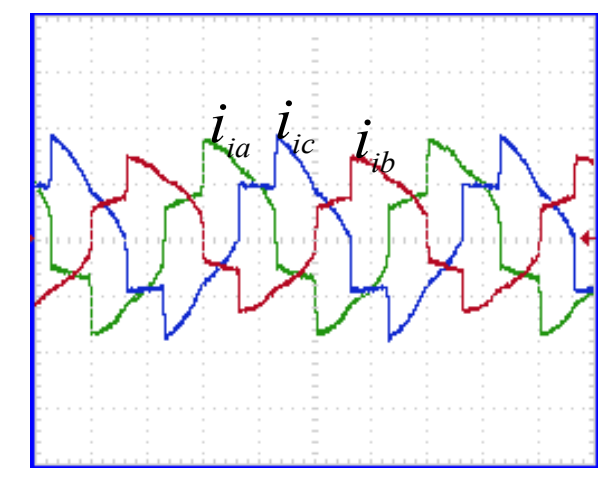

(b)

Fig. 19. Current injected by PV sourced inverter at PCC with CPC. (a) Simulated (10A/div; 20ms/div). (b) Experimental(2.5A/div; 20ms/div).

The proposed grid connected PV scheme is analyzed with a nonlinear load comprising of a phase to phase connected rectifier load $7.565 \mathrm{~kW}, 3.8 \mathrm{kVar}$ at the $\mathrm{PCC}$ at $0.5 \mathrm{~s}$

The nonlinear current drawn by the load is shown Fig. 16(a) and the captured experimental waveforms are shown in Fig. 16(b). The spikes in the experimental load current are due to the power electronic modules used in the experimental set up.

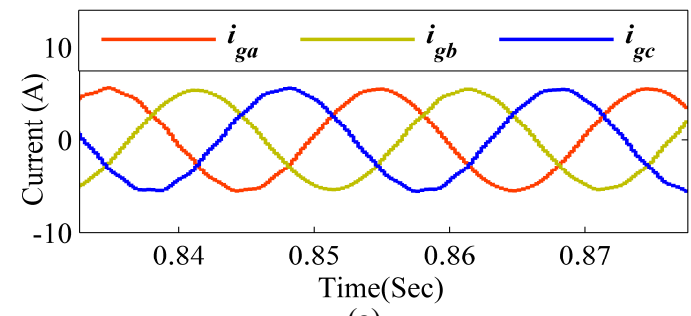

(a)

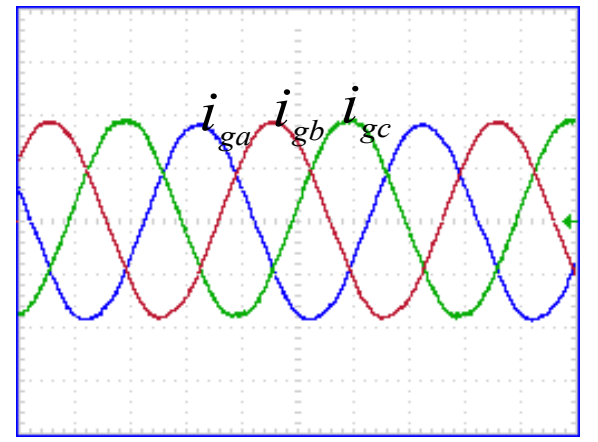

(b)

Fig. 20. Current exchanged from PCC to grid with $\mathrm{CPC}$ (a) Simulated (10A/div; 20ms/div). (b) Experimental(0.5A/div; $20 \mathrm{~ms} / \mathrm{div})$.

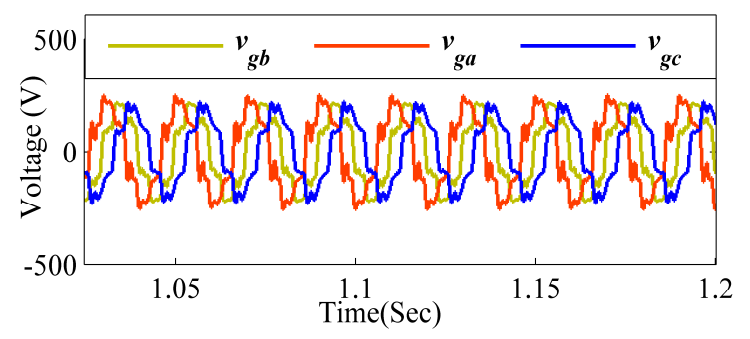

(a)

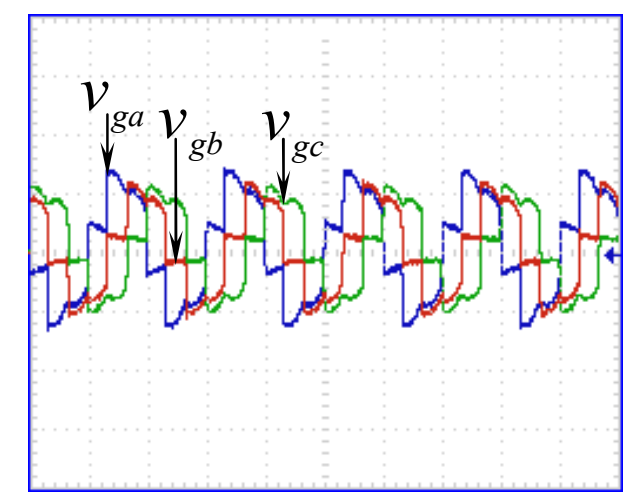

(b)

Fig. 21. Voltage at PCC with Nonlinear Unbalance Load (a) Simulated $\quad(250 \mathrm{~V} / \mathrm{div} ; \quad 20 \mathrm{~ms} / \mathrm{div})$ (b) Experimental(200V/div; 20ms/div)

The PV sourced inverter current in the DPC scheme is shown in Fig. 17. This indicates that it does not follow the unbalanced load current. As a result, a distorted current flows into the grid as in Fig. 18. However, with the proposed control the inverter current tracks the load current and hence 


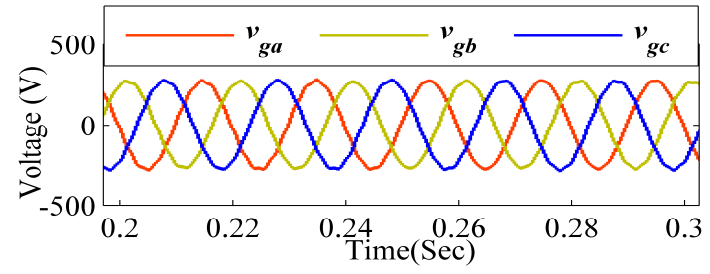

(a)

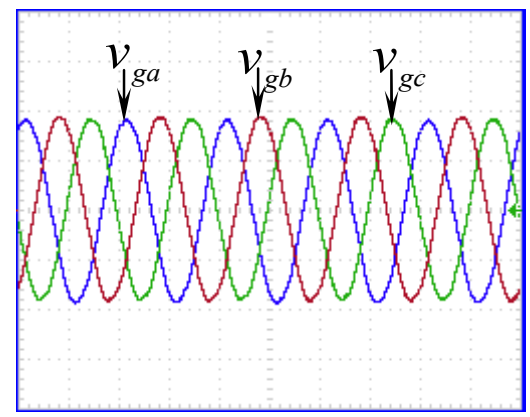

(b)

Fig. 22. Voltage at PCC during adding of NL Unbalance Load with CPC. (a) Simulated (250V/div; 20ms/div). (b) Experimental (150V/div; 20ms/div).

delivers a balanced current to the grid as indicated in Fig19(a) and the corresponding experimental waveforms in Fig.19(b). Hence perfect synchronization is achieved and the simulated and experimental grid currents are indicated in Fig. 20(a) and 20(b).

Case iii: Analysis of the proposed scheme in the autonomous mode with a nonlinear load at the PCC.

The working of the proposed CPC for a PV fed grid connected inverter is also tested in the autonomous mode. The ability of the proposed control PV system to work in this mode is presented and indicated in Fig. 6(b). The captured simulated and distorted load voltage waveforms at the PCC with a non-linear load are indicated in Fig. 21(a) and 21(b). However, with the proposed controller a smooth balanced load voltage is obtained and depicted in Fig. 22(a) and 22(b). This substantiates the ability of the controller to act in the islanding mode.

\section{CONCLUSIONS}

A dual control strategy comprising of VOC and DPC has been successfully developed for the grid integrated hybrid scheme comprising of a PV sourced grid connected inverter. A state space model of the suggested scheme with a CPC is developed in the DDSRF and an analysis is carried out for an unbalanced nonlinear load at the PCC. Exhaustive MATLAB-Simulink-ISE and Xilinx system generator based simulation results have been presented for the recommended scheme with an unbalance nonlinear load. The feasible operating limits of the CPC have been illustrated with phasor diagrams in both the grid and the autonomous modes of operation. Further, the working of the proposed controller has also been tested in the autonomous mode for an unbalanced nonlinear load. All of the results have been compared with the DPC scheme for the same configuration. The results clearly indicate that that unbalanced current drawn by the load is fully supplied by the inverter thereby injecting the balanced current into the grid. Thus the CPC has better capability when compared with the DPC scheme. The close resemblance of the simulated and observed experimental waveforms confirms the validity of the proposed model.

\section{REFERENCES}

[1] L. Fan, Z. Miao, and A. Domijan, "Impact of unbalanced grid conditions on PV systems," Power and Energy Society General Meeting, IEEE, 2010.

[2] L. Brunton, W. Rowley, R. Kulkarni,, and C. Clarkson, "Maximum power point tracking for photovoltaic optimization using ripple-based extremum seeking control," IEEE Trans. Power Electron., Vol. 25, No. 10, pp 2531-2540, Oct. 2010.

[3] A. Woyte, V. V. Thong, R. Belmans, and J. Nijs, "Voltage fluctuations on distribution level introduced by photovoltaic systems," IEEE Trans. Energy Convers., Vol. 21, No. 1, pp 202- 209, Mar. 2006.

[4] M. Dai, M. N. Marwali, J.-W. Jung, and A. Keyhani, "Power flow control of a single distributed generation unit with nonlinear local load," Power Systems Conference and Exposition, IEEE PES, 2004.

[5] F. Schonardie and C. Martins, "Application of the $d q 0$ transformation in the three-phase grid-connected pv systems with active and reactive power control," Sustainable Energy Technologies, IEEE International Conf. (ICSET), pp 18-23, 2008.

[6] H. Patel and V. Agarwal, "Investigations in to the performance of photovoltaics-based active filter configurations and their control schemes under uniform and non-uniform radiation conditions," IET Renewable Power Generation, Vol. 4, No. 1, pp. 12-22, Jan. 2010,

[7] M. P. Kazmierkowski, M. Jasinski, and G. Wrona, "DSP-based control of grid-connected power converters operating under grid distortions," IEEE Trans. Ind. Informat., Vol. 7, No. 2, pp 204-211, May 2011

[8] E. Ortjohann, A. Arias, and D. Morton, "Grid-forming three-phase inverters for unbalanced loads in hybrid power systems," Photovoltaic Energy Conversion, Conference Record of the IEEE 4th World Conf., Vol. 2, pp. 2396-2399, 2006.

[9] H. Nian and R. Zeng, "Improved control strategy for stand-alone distributed generation system under unbalanced and non-linear loads," IET Renewable Power Generation, Vol. 5, No. 5, pp. 323-331, Sep. 2011.

[10] J. Hu and Y. He, "Modeling and control of grid-connected voltage-sourced converters under generalized unbalanced operation conditions," IEEE Trans. Energy Convers., Vol. 23, No. 3, pp 903-913, Sep. 2008.

[11] F. Wang, J. L. Duarte, and M. A. M. Hendrix, "Design and analysis of active power control strategies for distributed generation inverters under unbalanced grid faults," IET 
Generation, Transmission \& Distribution, Vol. 4, No. 8, pp. 905-916, Aug. 2010.

[12] P. Rodriguez, A. Luna, and R. Munoz-Aguilar, "Control of power converters in distributed generation application under grid connected fault conditions, "Energy Conversion Congress and Exposition(ECCE), pp 2649-2656, 2011.

[13] P. Rodríguez, A. V. Timbus, R. Teodorescu, M. Liserre, and F. Blaabjerg, "Independent PQ control for distributed power generation systems under grid faults," IEEE Industrial Electronics, IECON 2006 - 32nd Annual Conf., pp 5185-5190, 2006.

[14] M. E. Ropp and S. Gonzalez., "Development of a MATLAB/Simulink model of a single-phase grid-connected photovoltaic system," IEEE Trans. Energy Convers., Vol. 24, No. 1, pp 195-202, 2009.

[15] D. Karlsson and D. J. Hill, "Modeling and identification of nonlinear dynamic loads in power systems," IEEE Trans. Power Syst., Vol. 9, No. 1, pp. 157-166, Feb. 1994.

[16] A. Borghetti, R. Caldon A. Mari, and C. A. Nucci, "On dynamic load model for voltage stability studies," IEEE Trans. Power Syst., Vol. 12, No. 1, pp 293-299, Feb. 1997.

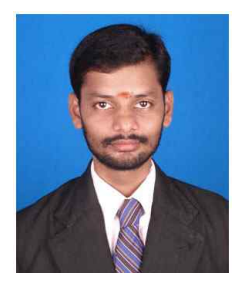

P. Sivakumar was born in Tiruchirapalli, India, on July 3, 1975. He did his U.G. and P.G. studies at the Regional Engineering College, Tiruchirapalli, India, and SASTRA University, Tamilnadu, India. He is presently working as an Assistant Professor of Electrical Engineering at the J.J. College of Engineering Technology, Tiruchirappalli, India. His current research interests include dispersed power generators based on PV and wind power generations, DG sourced power system optimizations and power electronics controls.

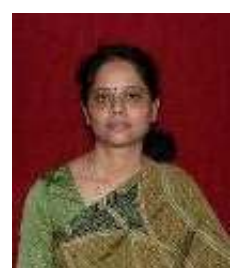

Meenakshi Sundaram Arutchelvi was born in Tiruchirappalli, India. She received her B.E. degree in Electrical Engineering from University of Vishvesvaraiah College of Engineering, Bangalore, India, in 1990, and her M.E. degree in Power Systems, and Ph.D. degree in Electrical Engineering both from the National Institute of Technology, Tiruchirappalli, India, in 1994 and 2007, respectively. She is presently working as a Professor of Electrical Engineering at the Saranathan College of Engineering, Tiruchirappalli, India. Her current research interests include dispersed power generators based on PV and wind power generators and power electronics. 